\title{
Optimized Research of Chinese Expenditure Structure on R\&D
}

\author{
Rongping Li \\ College of Economics and Management \\ Hebei University of Science and Technology \\ Shijiazhuang, China \\ 1965322@163.com
}

\author{
Yuanjie Li \\ College of Economics and Management \\ Hebei University of Science and Technology \\ Shijiazhuang, China \\ 854763920@qq.com
}

\begin{abstract}
With the development of economic globalization and integration of knowledge economy, science and technology's impact on economic growth, has become a focus of the whole society, especially in developing countries. Based on a detailed analysis of present situation of investment in science and technology from 2003 to 2012 in China, this paper uses the improved Cobb-Douglas utility function to optimize Chinese $R \& D$ expenditure structure. The results show that the present $R \& D$ expenditure structure is unreasonable. For the sake of improving the efficiency of science and technology, and promoting the development of economy, the Chinese government should increase R\&D investment proportion of Basic Research and Applied Research, and enhance the investment of R\&D in Higher Education.
\end{abstract}

Keywords-investment in R\&D; utility function; expenditure structure; optimized measuring; conclusions and recommendations.

\section{INTRODUCTION}

With the continuous development of knowledge economy, science and technology has become an important source of economic growth, and the inner motive power of national comprehensive national strength. In recent years, in order to improve the level of science and technology, many areas in our country have drawn up many development plans with the core of the development of high-tech ${ }^{[1-3]}$. Although these regional plans have distinguishing features, they all present a rising trend in the absolute amount of people and money input. Unfortunately, the increase of the absolute amount of government investment in science and technology has not obtained remarkable achievement, and even appears a phenomenon of low efficiency and severe waste of resources ${ }^{[4-7]}$. During 2003-2012, R\&D spending has risen almost fivefold, but the contribution rate of investment in science and technology to our country economic growth only increases 0.1 times, which shows that the investment in science and technology promotes the Chinese economics, but its role is not to achieve the desired effects. The reason is that the local government only focuses on increasing investment in science and technology, and ignores the importance of investment structure. The history of economic development of many countries also show that, it is not enough to just rely on increased investment in science and technology for the development of science and technology, and attention to the rationality of the investment structure also should be paid.

At present, the domestic existing researches on the structure of the investment in science and technology have focused on indirectly measuring it by comparing with developed countries or using utility function and other related concepts, etc. Such as, Cao Yanhua ${ }^{[8]}$ fond that Chinese R\&D input grows rapidly, but the overall level is still relatively low, and the input structure is not reasonable, by comparing China and Europe, the United States and Japan. Using specialized coefficient, Sun Yutao ${ }^{[9]}$ estimated eight major economic zones' input sources structure and implementation structure of science and technology in China from1999 to 2006. Song Yinqiu ${ }^{[10-11]}$ studied our country R\&D spending structure using the Cobb-Douglas utility function, although his method is more reasonable than others, he only analyzed the $R \& D$ expenditure proportion among the different properties, not involving R\&D expenditure proportion among different performers, and because of the analysis of Basic Research and Applied Research as a whole, his results is not detailed and comprehensive.

Based on this, according to R\&D investment in China from 2003 to 2012, we explore variation of technology investment structure, and optimize the structure of R\&D funding among different Properties and Performers of R\&D by using the improved Cobb-Douglas utility function, and then get a maximized proportion of investment structure of science and technology, so we can provide an important reference for the relevant government departments to develop scientific technology management policies, and improve the technological input-output efficiency.

\section{THE ANALYSIS OF THE PRESENT SITUATION OF INVESTMENT IN SCIENCE AND TECHNOLOGY}

The distribution of science and technology resources in China 2003-2012 is shown in Table I and Table II, from which we can see that, the total investment in science and technology increases year by year, yet, the input structure is changing.

\section{A. The proportion of Basic Research and Applied Research declines.}

In china, total R\&D expenditure increases year by year, the absolute amount of Basic Research and Applied Research of R\&D from 8.765 billion, 31.145 billion in 
2003 rise to 49.881 billion, 116.197 billion in 2012 , but their shares of the overall from $5.69 \%, 20.37 \%$ in 2003 decrease to $4.84 \%, 11.28 \%$ in 2012 (TABLE I). The R\&D personnel of full-time equivalent which are devoted to the both from 89700man-year, 260300man-year in 2003, rise to 212200 man-year, 383800 man-yearin 2012,respectively, but their shares of the overall from $8.19 \%, 23.77 \%$ in 2003, fall to $6.53 \%, 11.82 \%$ in 2012 , respectively. Thus, although the amount of investment in science and technology for Basic Research and Applied Research is rising, but the proportion of the total investment is falling.

B. The proportion of HigherEducation and $R \& D$ Institutions declines.

In China, total R\&D spending increases year by year, which is used in Higher Education and R\&D Institutions from 39.899 billion, 16.231 billion in 2003 rise to 154.893 billion, 78.056 billion in 2012, respectively, but their shares of the overall from $25.91 \%, 25.91 \%$ in 2003 decrease to $15.04 \%$ and $15.04 \%$ in 2012 . The R\&D personnel of full-time equivalent which are devoted to the both from 203900 man-year, 189300 man-year in 2003 , respectively, rise to 343500 man-year, 313500 man-year in 2012, but their shares of the overall from $18.62 \%, 17.29 \%$ in 2003 decrease to $10.58 \%, 9.66 \%$ in 2012 (TABLE II). This shows, although total $R \& D$ spending which is used in Higher Education and R\&D Institutions is rising, the proportion of the total investment is declining.

TABLE I. 2003-2012 CHINESE INPUT IN DIFFERENT PROPETTIES OF R\&D

$(\%)$

\begin{tabular}{|l|c|c|c|c|c|c|}
\hline \multirow{3}{*}{ Year } & \multicolumn{2}{|c|}{ Basic Research } & \multicolumn{2}{c|}{ Applied Research } & \multicolumn{2}{c|}{ Experimental Development } \\
\cline { 2 - 7 } & $\begin{array}{c}\text { Intramural } \\
\text { Expenditure } \\
\text { on R\&D }\end{array}$ & $\begin{array}{c}\text { Full-time } \\
\text { Equivalent of } \\
\text { R\&D Personnel }\end{array}$ & $\begin{array}{c}\text { Intramural } \\
\text { Expenditure } \\
\text { on R\&D }\end{array}$ & $\begin{array}{c}\text { Full-time } \\
\begin{array}{c}\text { Equivalent of } \\
\text { R\&D Personnel }\end{array}\end{array}$ & $\begin{array}{c}\text { Intramural } \\
\text { Expenditure } \\
\text { on R\&D }\end{array}$ & $\begin{array}{c}\text { Full-time } \\
\text { Equivalent of } \\
\text { R\&D Personnel }\end{array}$ \\
\hline 2003 & 5.69 & 8.19 & 20.23 & 23.77 & 74.08 & 68.04 \\
2004 & 5.96 & 9.61 & 20.37 & 24.17 & 73.67 & 66.22 \\
2005 & 5.36 & 8.46 & 17.70 & 21.77 & 76.95 & 69.78 \\
2006 & 5.19 & 8.74 & 16.28 & 19.95 & 78.53 & 71.31 \\
2007 & 4.70 & 7.95 & 13.29 & 16.47 & 82.01 & 75.57 \\
2008 & 4.78 & 7.83 & 12.46 & 14.72 & 82.76 & 77.45 \\
2009 & 4.66 & 7.18 & 12.60 & 13.76 & 82.75 & 79.06 \\
2010 & 4.59 & 6.80 & 12.66 & 13.14 & 82.75 & 80.06 \\
2011 & 4.74 & 6.70 & 11.84 & 12.24 & 83.42 & 81.07 \\
2012 & 4.84 & 6.53 & 11.28 & 11.82 & 83.87 & 81.65 \\
\hline
\end{tabular}

TABLE II. 2003-2012 CHINESE INPUT IN DIFFERENT PERFORMERS OF R\&D

\begin{tabular}{|c|c|c|c|c|c|c|}
\hline \multirow[b]{2}{*}{ Year } & \multicolumn{2}{|c|}{ Higher Education } & \multicolumn{2}{|c|}{ R\&D Institutions } & \multicolumn{2}{|c|}{ Enterprises and Others } \\
\hline & $\begin{array}{c}\text { Intramural } \\
\text { Expenditure } \\
\text { on } R \& D\end{array}$ & $\begin{array}{c}\text { Full-time } \\
\text { Equivalent of } \\
R \& D \\
\text { Personnel }\end{array}$ & $\begin{array}{c}\text { Intramural } \\
\text { Expenditure } \\
\text { on } R \& D\end{array}$ & $\begin{array}{c}\text { Full-time } \\
\text { Equivalent of } \\
R \& D \\
\text { Personnel }\end{array}$ & $\begin{array}{c}\text { Intramural } \\
\text { Expenditure } \\
\text { on } R \& D\end{array}$ & $\begin{array}{c}\text { Full-time } \\
\text { Equivalent of } \\
R \& D \\
\text { Personnel }\end{array}$ \\
\hline 2003 & 10.54 & 17.29 & 25.91 & 18.62 & 63.54 & 64.09 \\
\hline 2004 & 10.22 & 18.40 & 21.96 & 17.64 & 67.83 & 63.96 \\
\hline 2005 & 9.89 & 16.64 & 20.94 & 15.77 & 69.17 & 67.58 \\
\hline 2006 & 9.22 & 16.14 & 18.89 & 15.44 & 71.89 & 68.42 \\
\hline 2007 & 8.48 & 14.62 & 18.54 & 14.72 & 72.98 & 70.66 \\
\hline 2008 & 8.45 & 13.58 & 17.58 & 13.23 & 73.97 & 73.19 \\
\hline 2009 & 8.07 & 12.01 & 17.17 & 12.10 & 74.77 & 75.89 \\
\hline 2010 & 8.46 & 11.34 & 16.80 & 11.49 & 74.74 & 77.16 \\
\hline 2011 & 7.93 & 10.38 & 15.04 & 10.95 & 77.03 & 78.67 \\
\hline 2012 & 7.58 & 9.66 & 15.04 & 10.58 & 77.38 & 79.76 \\
\hline Total & 8.39 & 12.98 & 17.19 & 13.14 & 74.42 & 73.88 \\
\hline
\end{tabular}

\section{OPTIMIZATION MEASURES OF INVESTMENT} STRUCTURE IN CHINESE SCIENCE AND TECHNOLOGY

In economics, we commonly use utility to represent consumers' satisfaction of goods. Utility, refers to the consumers' satisfaction gained by the consuming, the greater the utility, the bigger satisfaction from goods; on the contrary, the opposite will appear. This article will draw lessons from the utility theory to analyze the satisfaction gained by the R\&D spending. Something can be seen from TABLE I and II that our R\&D spending remains reciprocal relationship among the different properties and performers of R\&D spending, just like indifference curve, which different proportion of $R \& D$ 
spending can also bring the same economic effects, yet the satisfaction of different indifference curve is not the same.

With the development of knowledge economy, more and more attention is paid to the investment of science and technology, it become the focus of in many countries how to distribute $R \& D$ expenditure among the different Properties and Performers to achieve the greatest economic effects.

\section{A. Set of the model}

In calculating the allocation proportion of input of science and technology among three different properties researches, we regard three different properties of $R \& D$ activities as three kinds of goods in the improved CobbDouglas utility function, the utility from the combination of three kinds of R\&D activities as the economic results of three different properties, namely the objective function. Established a model as the following,

$$
\left\{\begin{array}{l}
\max U(X, Y, Z)=X^{\alpha} \times Y^{\beta} \times Z^{\gamma} \\
\text { s.t. } P_{X} X+P_{Y} Y+P_{Z} Z=R D \\
\alpha+\beta+\gamma=1 \\
\alpha>0, \beta>0, \gamma>0
\end{array}\right.
$$

Among them, $X, Y, Z$ represent $\mathrm{R} \& \mathrm{D}$ expenditure on Basic Research, Applied Research and Experimental Development, $U(X, Y, Z)$ means the economic effects of three different properties of $\mathrm{R} \& \mathrm{D}$, respectively, $\alpha, \beta, \gamma$ represent the proportion of the overall which account for three kinds of R\&D activities, $P_{1}, P_{2}, P_{3}$ denote their capital cost or price, $R D$ is total investment. Obtained by solving the above model:

$$
X: Y: Z=\frac{\alpha}{P_{X}}: \frac{\beta}{P_{Y}}: \frac{\gamma}{P_{Z}}
$$

Equation (2) is the optimal ratio of the scale of R\&D investment in Basic Research, Applied Research and Experimental Development whose combination achieves maximized economic effects.

In measuring the most optimal structure among Higher Education, R\&D institutions, and Enterprises and Others, we use the same idea: $X, Y, Z$ represent R\&D spending in them, $U(X, Y, Z)$ means the economic effects of three of performers of $\mathrm{R} \& \mathrm{D}, \alpha, \beta, \gamma$,respectively, represent their proportion of the overall, $P_{1}, P_{2}, P_{3}$ denote their capital cost or price, $R D$ is total investment.

\section{B. Measure the optimized structure proportion}

Using the above model to measure the optimal structure ratio, is to determine the value of $\alpha, \beta, \gamma, P_{1}, P_{2}, P_{3}$ in the model. All the proportion $\alpha, \beta, \gamma$ can be got from Table I and Table II, therefore, the cost of capital or price- $P_{1}, P_{2}, P_{3}$ become the focus of the measurement. Since $X, Y, Z$ are not the product in the usual sense, they don't have price in the usual sense, and we use an alternative method commonly used in economics that a per capita cost of technology activities substitute their cost of capital. In this paper, we use R\&D expenditure from 2003-2012 and the corresponding R\&D personnel expenses to calculate per capita cost of the R\&D activities, and the value obtained through the sum of $R \& D$ expenditure and the sum of $R \& D$ personnel expenses accounts for overall per capita costs. Specific calculation results of per capita costs are shown in TABLE III.

- (1) The proportions- $\alpha, \beta, \gamma$-are $4.87 \%, 13.26 \%$, $81.87 \%$ (TABLE I), respectively, which denote R\&D spending devoted to Basic Research, Applied Research and Experimental Development of the overall, and their corresponding cost of capital- $P_{1}, P_{2}, P_{3}$-are: RMB 161300 / person, RMB 210300 / person, RMB 264500 / person (TABLE III). Therefore, in order to maximize the economic effects, the optimal allocation ratio of $\mathrm{R}$ $\& \mathrm{D}$ expenditure among three properties of researches is: $X: Y: Z=1: 2: 10$.

- (2) The proportions- $\alpha, \beta, \gamma$-are $8.39 \%, 17.19 \%$, $74.42 \%$ (TABLE II), respectively, which denote R\&D spending devoted to Higher Education, R\&D Institutions, and Enterprises and Others which account for the overall, and their corresponding cost of capital- $P_{1}, P_{2}, P_{3}$-are: RMB 160,400 / person, RMB 325,000 / person, RMB 250,100/ person (TABLE III). Therefore, in order to maximize the economic effects, the optimal allocation ratio of $\mathrm{R} \& \mathrm{D}$ expenditure among three performers of researches is $: X: Y: Z=1: 1: 5.62$.

Two conclusions can be gained through the model result:

- (1) Compared with Experimental Development, financial investment of Basic Research and Applied Research is serious shortage. TABLE I shows that the proportion of different Properties of researches in $\mathrm{R} \& \mathrm{D}$ spending is: 1:2.72:16.81, but, depending on the analysis of the utility model, the most optimal allocation proportion is 1:2:10 when the economic effects of $R \& D$ spending is maximized. Thus, in China, the proportion of investment is obviously low in Basic Research and Applied Research and too high in Experimental Development.

- (2) The ratio of scientific research expenditure devoted to Higher Education is too low, the ratio of R\&D Institutions is high. From TABLE II, we can see that the proportion of different performers in $\mathrm{R} \& \mathrm{D}$ spending is: 1:2.04:8.84, but, depending on the analysis of the utility model, optimal allocation proportion is 1:2:10 when the economic effects of spending on $R \& D$ is maximized. This fully shows that, on the one hand, our country has achieved scientific research model of "Corporate body on R\&D" in science and technology activities; on the other hand, our research funding for Higher Education is low, and a little high in R\&D Institutions. 
TABLE III 2003-2012 PER CAPITA COSTS OF R \& D

RAM Ten thousands/person

\begin{tabular}{|c|c|c|c|c|c|c|}
\hline \multirow{2}{*}{ Year } & \multicolumn{3}{|c|}{ Properties } & \multicolumn{3}{|c|}{ Performers } \\
\hline & $\begin{array}{c}\text { Basic } \\
\text { Research }\end{array}$ & $\begin{array}{c}\text { Applied } \\
\text { Research }\end{array}$ & $\begin{array}{c}\text { Experimental } \\
\text { Development }\end{array}$ & $\begin{array}{c}R \& D \\
\text { institutions }\end{array}$ & $\begin{array}{c}\text { Higher } \\
\text { Education }\end{array}$ & Enterprises and Others \\
\hline 2003 & 9.77 & 11.97 & 15.31 & 19.57 & 8.58 & 13.94 \\
\hline 2004 & 10.58 & 14.37 & 18.98 & 21.23 & 9.47 & 18.09 \\
\hline 2005 & 11.37 & 14.59 & 19.80 & 23.84 & 10.67 & 18.37 \\
\hline 2006 & 11.86 & 16.31 & 22.01 & 24.46 & 11.41 & 21.00 \\
\hline 2007 & 12.64 & 17.24 & 23.19 & 26.92 & 12.39 & 22.07 \\
\hline 2008 & 14.34 & 19.88 & 25.10 & 31.19 & 14.63 & 23.74 \\
\hline 2009 & 16.43 & 23.17 & 26.50 & 35.93 & 17.01 & 24.95 \\
\hline 2010 & 18.68 & 26.63 & 28.58 & 40.42 & 20.62 & 26.79 \\
\hline 2011 & 21.31 & 29.15 & 31.01 & 41.39 & 23.02 & 29.50 \\
\hline 2012 & 23.51 & 30.28 & 32.58 & 45.09 & 24.90 & 30.77 \\
\hline Total & 16.13 & 21.03 & 26.45 & 32.50 & 16.04 & 25.01 \\
\hline
\end{tabular}

Notes: Datas from the China Statistical Yearbook 2004-2013

\section{RECOMMENDATIONS}

Something we can see from the above analysis, that just relying on increasing of the total amount is not enough, and some measures must be taken to adjust the structure of investment in science and technology, if we want to maximize output of science and technology, and improve the competitiveness of science and technology. Specifically, the greatest efforts to improve capital efficiency of R\&D from the following two aspects can be tried:

\section{A. Improve proportion of the $R \& D$ funds devoted to Basic Research and Applied Research.}

Basic Research and Applied Research are the foundation for Experimental Development, and very important to enhance competitiveness of science and technology, and are essential for a national or regional economic development and social progress. Developed countries in the process of the development of science and technology, also attaches great importance to them, based on our nation's current level of development of science and technology, enhancing the investment to both is more important. The government should make full use of tax leverage to guide the science and technology funds into Basic Research and Applied Research, to lay a solid foundation for Experimental Development; Enterprise which is the main body of investment in science and technology, is an important source of scientific research funds, and should give full play to their roles, increase the enterprise's support for both, especially for large enterprises within two kinds of researches, to improve their own technological prowess.

\section{B. Increase the investment of $R \& D$ funds of Higher Education.}

Higher Education is the main carrier of science and technology personnel cultivation, and plays an irreplaceable role in economic growth and development of science and technology. During the process of modernization of science and technology in both developed and developing countries, increasing R\&D investment in Higher Education has always been an important subject. Governments should increase research expenditure in it to ensure the material supplies for the scientific research activities; Relying on their advantages in human resources, Colleges and universities should strengthen the cooperation with enterprises or foreign scientific research organization to increase the amount of their financial investment on $R \& D$, ensure the smooth progress in scientific researches, and promote the healthy and rapid development of science and technology in our country.

\section{ACKNOWLEDGMENT}

We are grateful to anonymous referees and the handling editor for helpful comments and suggestions. The financial support from Hebei province natural science foundation, is also gratefully acknowledged.

\section{REFERENCES}

[1] Wu Yun, "Impact of Governmental Investment on Science \& Technology Innovation: EmpiricalTest Based on Panel Data of 40 countries from 1982 to 2010, ” SCIENCE OF SCIENCE AND MANAGEMENT OF S. \& T. , Vol. 35, pp. 16-21, 2014

[2] Xu Qiaoling , "Efficiency Evaluation on Science and Technology Input and Output-Based on DEA - the BCC Model and SE CCR Model, " Science and Technology Management Research,pp.66-70,2014.

[3] Lu Yuedong, Shen Yuan and Duan Zhongxian, “Evaluation on Provincial Financial Science and Technology Input-output Performance in China," JOURNAL OF DIALECTICS OF NATURE, Vol.35 ,pp.88-95,2013.

[4] Fan Xing , Ma Shucai and Zhu Lianzhou, "Comparative Analysis of Science and Technology Activities Input and Output Efficiency" Science and Technology Management R esearch, pp.79-83, 2013.

[5] Rong-ping Li, Jing-ru Wu and Hui-dong Cui. "Evaluation and Analysis to Regional Enterprise Technology Innovation Effectiveness Based on DEA ," 2009 International Conference on Machine Learning and Cybernetics,.2009:2543 -2548

[6] Hu Enhua, Liu Hong, and Zhang Long, "An empirical analysis of economic effectss of Chinese science and technology investment ," Science Research Management, vol. 4, pp. 71-75,2004

[7] Wu Hecheng and Zheng Chuiyong, "An empirical analysis on the relative efficiency of the input - output of science and technology,"Scientific Management Research, vol. 03, pp. 93-96, 2003 . 
[8] Cao Yanhua and Yan Shu, "The International Comparison and Suggestions of Investment in Science and Technology of Developed Country and China," Science and Technology Management Research, vol. 24, pp. 21-24, 2012.

[9] Sun Yutao, Liu Fengchao and Xu Qian, "Analysis on the Structure Evolution of Science and Technology Input in China' s Eight Major Economic Regions Based on the Specialization Coefficient," Management Review, vol. 02, pp. 80-86, 2011.

[10] Song Yinqiu, "Study on the Rationality of Structure for R\&D Expenditure,"Statistical Research, vol. 26, pp. 53-55, 2009.

[11] Song Yinqiu and Lv Ping, Huang Wen, "The structure comparison of Sino-US R\&D expenditure ,"Science Research Management, vol. 04, pp. 102-107, 2012. 